\title{
CULTURA E APRENDIZAGEM ORGANIZACIONAIS: EXPLORANDO RELAÇÕES EM UMA ORGANIZAÇÃO PÚBLICA
}

\author{
ORGANIZATIONAL CULTURE AND LEARNING: EXPLORING RELATIONS IN A PUBLIC ORGANIZATION \\ CULTURA Y APRENDIZAJE ORGANIZACIONALES: EXPLORANDO RELACIONES EN UNA \\ ORGANIZACIÓN PÚBLICA
}

\author{
GÉDSON MÁRIO BORGES DAL FORNO \\ Universidade Federal de Santa Maria - Brasil \\ gedson_df@hotmail.com \\ ORCID: https://orcid.org/0000-0001-6722-9502 \\ JEFFERSON MENEZES DE OLIVEIRA \\ Universidade Federal de Santa Maria - Brasil \\ jeffersonmenezes@gmail.com \\ ORCID: https://orcid.org/0000-0003-1937-8751 \\ VANIA DE FÁTIMA BARROS ESTIVALETE
Universidade Federal de Santa Maria - Brasil
vaniaestivalete@ufsm.br
ORCID: https://orcid.org/0000-0002-3277-8613
}

FELIPE MARTINS MÜLLER

Universidade Federal de Santa Maria - Brasil

felipe@inf.ufsm.br

ORCID: https://orcid.org/0000-0003-0062-5863

Submetido em: 08/03/2018

Aprovado em: 24/09/2018

Doi: alcance.v25n3(Set/Dez).p330-348

\section{RESUMO}

O objetivo do estudo foi identificar as relações existentes entre a cultura organizacional (CO) e a aprendizagem organizacional (AO) sob a perspectiva dos servidores de uma instituição federal de ensino localizada na Região Sul do Brasil. Com caráter descritivo, o estudo foi conduzido pelo método survey. Os resultados identificaram os fatores comumente adotados pelos servidores no que tange à $\mathrm{CO}$, os fatores potencializadores e dificultadores da $\mathrm{AO}$ e, por fim, as relações entre os fatores destes construtos. $\mathrm{O}$ estudo das correlações entre $\mathrm{CO}$ e $\mathrm{AO}$ permitiu identificar a existência de associações entre a maior parte de seus fatores, sendo que as relações significativas positivas foram predominantes, revelando um entrelaçamento entre os temas.

Palavras-chave: Cultura, Aprendizagem, Comportamento Organizacional, Organizações Públicas.

\section{ABSTRACT}

The objective of this study was to identify the relationships between organizational culture and organizational learning, from the perspective of employees of a federal educational institution located in the South of Brazil. This descriptive study was conducted through a survey. The results identified the factors commonly adopted by the civil servants regarding organizational culture, the factors that potentiate and impede organizational learning, and, 
finally, the relationship between the factors of these constructs. The study of correlations between the constructs led us to identify the existence of associations between most of its factors, with significant positive relations being predominant, revealing an interweaving between the themes.

Key words: Culture, Learning, Organizational Behavior, Public Organizations.

\section{RESUMEN}

El objetivo del estudio fue identificar las relaciones existentes entre la cultura organizacional (CO) y el aprendizaje organizacional $(\mathrm{AO})$ en la perspectiva de los servidores de una institución federal de enseñanza ubicada en la región sur de Brasil. Con carácter descriptivo, el estudio fue conducido por el método survey. Los resultados identificaron los factores comúnmente adoptados por los servidores en lo que se refiere a la $\mathrm{CO}$, los factores potencializadores y dificultadores del AO y, por fin, las relaciones entre los factores de estos constructos. El estudio de las correlaciones entre $\mathrm{CO}$ y AO permitió identificar la existencia de asociaciones entre la mayor parte de sus factores, siendo que las relaciones significativas positivas fueron predominantes, revelando un entrelazamiento entre los temas.

Palabras clave: Cultura, Aprendizaje, Comportamiento Organizacional, Organizaciones Públicas.

\section{INTRODUÇÃO}

O interesse pela aprendizagem organizacional (AO) assumiu destaque entre meados dos anos 80 e início dos anos 90 , permanecendo fortalecido até os dias atuais. As últimas três décadas de esforços coletivos para entender o fenômeno deram uma compreensão mais matizada e, em alguns casos, sofisticada dos antecedentes, processos e consequências da aprendizagem organizacional (Lee, Rittiner \& Szulanski, 2016).

Argyris e Schön (1978; 1996) conceberam a aprendizagem organizacional como o processo identificador de falhas e incentivador de análise reflexiva no sentido de identificar possíveis correções, ou seja, enfatizam que a detecção de erros e sua correção são componentes centrais da aprendizagem oriunda do ato reflexivo. Sendo assim, pela concepção de que as organizações possuem um aprendizado codificado por inferências históricas transformadas em rotinas que orientam seu comportamento (Levitt \& March, 1988), entende-se que esta temática pode estar entrelaçada com a cultura organizacional (CO).

Schein $(1984 ; 2009)$ define cultura organizacional como sendo o padrão de pressupostos básicos que um determinado grupo concebeu, descobriu ou desenvolveu ao aprender a lidar com seus problemas de adaptação externa e integração interna. Uma vez considerados válidos, estes pressupostos podem ser ensinados a novos membros da organização, consolidando estratégias de conduta frente a problemas.

Entende-se plausível a verificação da relação existente entre cultura e aprendizagem organizacional, pelo entendimento de que uma cultura é sedimentada por meio da aprendizagem dos indivíduos formadores dos grupos, e esta aprendizagem ocorre de acordo com a cultura manifestada na organização (Dogson, 1993).

Nesse contexto, um dos grandes desafios das organizações, segundo Tonet (2008), é propiciar um ambiente favorável a uma cultura voltada ao compartilhamento de conhecimento que estimule a aprendizagem contínua das pessoas. Para isso, é necessário valorizar o que as pessoas sabem, a disposição para repassar 0 que sabem e a receptividade para assimilar o que não sabem.

A interação entre os temas possui assento nos apontamentos de Weick e Westley (2004), os quais indicam que os aspectos culturais da organização podem fundamentar as discussões sobre a aprendizagem organizacional. Segundo esses autores, a cultura é importante para a aprendizagem, porque age como símbolo e como armazenadora de experiência passada (Normann, 1985) e funciona como um instrumento para comunicar essa aprendizagem a toda a organização. Considerando a aprendizagem 0 ato de evidenciar a experiência contínua, o que as pessoas aprendem são significados intersubjetivos inseridos na cultura.

Sendo assim, torna-se plausível o estudo acerca das relações existentes entre aprendizagem e cultura organizacional. Presume-se que um novo aprendizado, ao tornar-se coletivo, poderá levar a modificações na cultura organizacional. Inversamente, entende-se que mudanças na cultura organizacional poderão conduzir a novas maneiras de aprender ou influenciar no aprendizado dos membros da organização. 
A relevância dos temas em estudo, aliada ao interesse cada vez maior pela melhoria dos serviços prestados e das rotinas utilizadas pelas organizações públicas, tornam coerente a realização de avaliações constantes, bem como a análise das relações entre cultura e aprendizagem organizacional no setor público.

Por escopo, o presente estudo é realizado no âmbito de uma instituição federal de ensino superior localizada na Região Sul do Brasil, organização pública dotada de peculiaridades no diz respeito a formas de hierarquia, progressão funcional, ingresso e estabilidade. Nesse contexto, a presente pesquisa guia-se pelo seguinte questionamento: quais as relações existentes entre a cultura e a aprendizagem organizacional sob a perspectiva dos servidores de uma instituição federal de ensino superior?

Para responder à questão de pesquisa, previamente, serão identificados os fatores comumente adotados pelos servidores de uma instituição federal de ensino superior no que tange à cultura organizacional, assim como os fatores potencializadores e dificultadores da aprendizagem na organização. Dessa forma, será possível atender ao objetivo geral da pesquisa, o qual consiste em identificar as relações entre os fatores de cultura organizacional e de aprendizagem organizacional em uma organização pública.

Este artigo segue estruturado com a fundamentação teórica concernente aos temas pesquisados (Seção 2), os procedimentos metodológicos utilizados na pesquisa (Seção 3), os resultados e as suas análises (Seção 4) e, por fim, as considerações finais do estudo (Seção 5).

\section{FUNDAMENTAÇÃO TEÓRICA}

Esta seção aborda os pressupostos teóricos relacionadas às temáticas em estudo. A primeira subseção aborda a Cultura Organizacional (CO) e a segunda aborda a Aprendizagem Organizacional (AO).

\subsection{Cultura Organizacional}

Toda organização possui uma cultura, que consiste em um conjunto de suposições, valores e normas que conduzem suas atividades. A CO tem sido definida de várias maneiras e relacionada a diversos fatores, tais como estilos de gestão, sistemas de recompensa, estilos de comunicação e modos de tomada de decisão (Tang \& Zhang, 2016). Sweringa e Wierdsma (1995, p. 12), por exemplo, definem cultura organizacional como "a soma combinada das opiniões individuais, dos valores compartilhados e das normas dos membros da organização".

Considerado um dos maiores autores sobre o assunto, Schein (1984) concebia que o fato de conhecer profundamente uma organização, participando do seu cotidiano, não proporcionaria, necessariamente, 0 entendimento de como sua cultura surgiu, como ela veio a ser o que é, ou como ela poderia ser alterada em determinadas situações. Nesse sentido, não existe uma cultura, a menos que exista um grupo que a "possui", sendo esse um conjunto de pessoas (1) que estão juntas o tempo suficiente para ter problemas significativos compartilhados, (2) que tiveram oportunidades para resolver esses problemas observando os efeitos de suas soluções e (3) que receberam novos membros. Assim, a cultura do grupo não pode ser determinada a menos que haja um conjunto bem definido de pessoas com uma história compartilhada (Schein, 1984).

Quando uma organização é constituída por subgrupos, sua cultura será formada pelas diversas subculturas existentes. Sendo assim, tornam-se plausíveis a localização dos subgrupos estáveis, a assimilação das culturas que eles desenvolveram e o modo como estas culturas combinam-se em um único grupo. A cultura unificada poderá ser muito homogênea ou heterogênea, sendo determinada pelo grau de semelhanças ou diferenças entre os subgrupos da organização (Schein, 1984).

Em uma revisão ao conceito de Schein (1984), apresentado na introdução deste artigo, Fleury (1996) infere que a $\mathrm{CO}$ é um conjunto de valores e pressupostos básicos expresso em elementos simbólicos, que em sua capacidade de ordenar, atribuir significações, construir a identidade organizacional tanto age como elemento de comunicação e consenso, como oculta e instrumentaliza as relações de dominação nas organizações.

No sentido de operacionalizar uma forma de avaliar os elementos da CO, Ferreira, Assmar, Estol, Helena e Cisne (2002) desenvolveram um instrumento, que se fundamentou na identificação dos valores e das práticas que configuram a cultura de uma organização. Esse instrumento tomou por base a análise de conteúdo de entrevistas realizadas com diretores ou gerentes de diversas organizações, sendo a versão inicial da escala composta por 126 afirmativas, respondidas por 823 indivíduos. Após as análises realizadas, resultando em uma 
versão de 94 itens, as autoras concluíram que as características psicométricas do instrumento recomendam a sua utilização em pesquisas brasileiras destinadas à avaliação da cultura organizacional.

Este instrumento, validado por Ferreira et al. (2002), foi denominado de Instrumento Brasileiro para Avaliação da Cultura Organizacional (IBACO), o qual conjuga sete fatores em sua concepção, sendo quatro referentes a valores e os outros três associados a práticas organizacionais. As descrições destes fatores, ou dimensões, estão dispostas no Figura 1.

\begin{tabular}{|l|l|c|}
\hline Fator & Descrição & $\begin{array}{c}\mathbf{N}^{0} \\
\text { itens }\end{array}$ \\
\hline $\begin{array}{l}\text { Valores de profissionalismo } \\
\text { cooperativo }\end{array}$ & $\begin{array}{l}\text { Relacionados à valorização dos colaboradores que executam suas tarefas } \\
\text { com eficácia e competência, demonstrando espírito de colaboração, } \\
\text { dedicação, profissionalismo e capacidade de iniciativa. }\end{array}$ & 23 \\
\hline $\begin{array}{l}\text { Valores de rigidez na estrutura } \\
\text { hierárquica de poder }\end{array}$ & $\begin{array}{l}\text { Referentes a valores presentes em organizações definidas por um sistema } \\
\text { de autoridade centralizado e autoritário que dificulta o crescimento } \\
\text { profissional e o reconhecimento do elemento humano. }\end{array}$ & 13 \\
\hline $\begin{array}{l}\text { Valores de profissionalismo } \\
\text { competitivo e individualista }\end{array}$ & $\begin{array}{l}\text { Denotam a valorização da competência, do desempenho e da eficácia } \\
\text { individuais na execução de tarefas para a obtenção dos objetivos desejados. }\end{array}$ & 8 \\
\hline $\begin{array}{l}\text { Valores associados à satisfação } \\
\text { e bem-estar dos empregados }\end{array}$ & $\begin{array}{l}\text { Referentes à valorização do bem-estar, da satisfação e da motivação dos } \\
\text { colaboradores, isto é, da humanização do local de trabalho de modo a torná- } \\
\text { lo agradável e prazeroso. }\end{array}$ & 11 \\
\hline Práticas de integração externa & $\begin{array}{l}\text { Associados a práticas voltadas para o planejamento estratégico, a tomada } \\
\text { de decisão e o atendimento ao cliente externo. }\end{array}$ & 17 \\
\hline $\begin{array}{l}\text { Práticas de recompensa e } \\
\text { treinamento }\end{array}$ & $\begin{array}{l}\text { Relacionados a práticas vinculadas aos clientes internos e aos sistemas de } \\
\text { recompensas e treinamento adotados pela empresa. }\end{array}$ & 14 \\
\hline $\begin{array}{l}\text { Práticas de promoção do } \\
\text { relacionamento interpessoal }\end{array}$ & $\begin{array}{l}\text { Referente a práticas orientadas para a promoção das relações interpessoais } \\
\text { e satisfação dos colaboradores. }\end{array}$ & 8 \\
\hline
\end{tabular}

Figura 1: Fatores do IBACO

Fonte: Elaborada a partir de Ferreira et al. (2002) e Ferreira e Assmar (2008).

Vale ressaltar que existe uma versão reduzida da escala IBACO, desenvolvida para as situações em que se deseja um instrumento de medida mais sucinto, a qual foi compilada a partir dos itens que apresentaram as maiores cargas fatoriais na versão original, resultando em 30 itens (Ferreira \& Assmar, 2008).

\subsection{Aprendizagem Organizacional}

Conforme Nogueira e Odelius (2015), as referências mais frequentes e influentes para os estudos de aprendizagem organizacional (AO) são Argyris e Schön (1978), Daft e Weick (1984), Fiol e Lyles (1985) e Levitt e March (1988). Argyris e Schön (1978) destacam-se pelo entendimento de que a aprendizagem é um processo pelo qual a organização detecta e corrige erros. Daft e Weick (1984) consideram que a aprendizagem possui como base a interpretação organizacional, a qual é realizada a partir do conhecimento compartilhado. Fiol e Lyles (1985) entendem que a $\mathrm{AO}$ consiste no desenvolvimento de ideias, conhecimento e associações entre ações passadas, a efetividade dessas ações e ações futuras. Para Levitt e March (1988), a transferência de nível de aprendizagem do individual para o organizacional ocorre quando se modificam, criam-se ou se alteram rotinas organizacionais. Nesse sentido, a AO é baseada na rotina, possui dependência histórica e é orientada a resultados.

Embora admitindo a existência de uma multiplicidade de definições, Probst e Büchel (1997, p. 15) definem a AO como "o processo pelo qual o conhecimento da organização e as mudanças de base de valor levam à melhoria da capacidade de resolução de problemas e à capacidade de ação". Segundo esses autores, a organização é formada por indivíduos que aprendem. Nesse entendimento, a aprendizagem individual é concebida como um pré-requisito para a aprendizagem organizacional (Argyris \& Schön, 1996; Probst \& Büchel, 1997; Kim, 1998). Entretanto, não se pode considerar a aprendizagem organizacional como resultante do cumulativo da aprendizagem individual dos membros da organização. As organizações podem aprender independentemente de qualquer indivíduo específico, mas não podem aprender independentemente de todos os indivíduos (Kim, 1993).

Helmsing (2001) e Antonello (2006) concebem a AO como um processo permanente de construção e desenvolvimento de competências, tendo por base a apropriação de novos conhecimentos direcionados ao 
desenvolvimento de novos mapas cognitivos. Essa construção possibilita que as pessoas compreendam a si próprias, a organização e o ambiente envolto, de forma a estabelecerem novas atitudes em relação ao seu trabalho, à sua organização e ao mundo externo.

Reconhecendo a complexidade do processo de AO, Wang e Ahmed (2003) identificaram cinco focos que devem ser considerados em sua conceituação e operacionalização: foco na coletividade de aprendizagem individual; foco no processo ou sistema; foco na cultura ou metáfora; foco em gestão do conhecimento e foco na melhoria contínua.

O foco na coletividade de aprendizagem individual considera os indivíduos como "agentes" fundamentais à aprendizagem organizacional. 0 foco no processo ou sistema considera que aprendizagem organizacional é 0 processo pelo qual as organizações a compreendem e gerenciam as suas experiências. $O$ foco na cultura ou metáfora considera que a cultura serve como um mecanismo que orienta e molda os valores, comportamentos e atitudes dos funcionários, possuindo influências sobre a aprendizagem organizacional. 0 foco em gestão do conhecimento aponta que a aprendizagem organizacional necessita estar essencialmente ligada à criação de conhecimento. Por fim, o foco na melhoria contínua denota a ideia de que a aprendizagem organizacional deve ser um processo contínuo (Wang \& Ahmed, 2003).

Sendo assim, a AO não é simplesmente uma coletividade de processos individuais de aprendizagem. Percebe-se que ela envolve uma complexidade de interações entre indivíduos, organizações e seus contextos. Por tais motivos, a AO apresenta-se como uma área interdisciplinar e, mesmo não contando com uma teoria amplamente aceita, vem avançando e apresentando pontos de consenso que a estabelecem como um campo de conhecimento (Takahashi \& Fischer, 2009; Nogueira \& Odelius, 2015).

No que tange à mensuração da AO, Goh e Richard (1997) utilizaram, a partir de um estudo empírico, a composição de vários elementos considerados relevantes para a aprendizagem organizacional. Este estudo resultou no desenvolvimento de um instrumento de medida chamado Organizational Learning Scale (OLS).

De acordo com Goh e Richard (1997), a dificuldade em mensurar a capacidade de aprendizagem existente na organização constitui um dos maiores problemas da implementação da aprendizagem organizacional. Para a elaboração da OLS, Goh e Richard (1997) identificaram e tomaram como base cinco dimensões de características e práticas gerenciais favoráveis à aprendizagem organizacional, as quais se encontram especificadas no Figura 2.

\begin{tabular}{|c|c|c|c|}
\hline Dimensões & Definição & \multicolumn{1}{c|}{$\begin{array}{c}\text { Características e/ou } \\
\text { Práticas de gestão }\end{array}$} \\
\hline $\begin{array}{c}\text { Clareza de } \\
\text { Propósito } \\
\text { e Missão }\end{array}$ & $\begin{array}{c}\text { Grau de entendimento que os funcionários } \\
\text { possuem da missão e dos propósitos da } \\
\text { organização e de como eles podem contribuir } \\
\text { para seu alcance. }\end{array}$ & $\begin{array}{l}\text { Compreensão do propósito da organização } \\
\text { pelos funcionários; os funcionários sabem como } \\
\text { seu trabalho pode contribuir para o alcance das } \\
\text { metas organizacionais. }\end{array}$ \\
\hline $\begin{array}{c}\text { Empowerment e } \\
\text { Comprometimento } \\
\text { da Liderança }\end{array}$ & $\begin{array}{c}\text { Papel do líder na organização e na promoção } \\
\text { de um clima de aprendizagem e de uma } \\
\text { cultura de mudança por meio do seu } \\
\text { comportamento. }\end{array}$ & $\begin{array}{l}\text { Propiciar feedback; o gestor deve: estar aberto a } \\
\text { críticas; } \\
\text { Admitir erros de forma construtiva; permitir que } \\
\text { os funcionários participem das decisões } \\
\text { assumindo os alguns riscos. }\end{array}$ \\
\hline $\begin{array}{c}\text { Experimentação } \\
\text { fexperimentar novos processos e métodos de } \\
\text { trabalho. }\end{array}$ & $\begin{array}{l}\text { Suporte paramento } \\
\text { desenvolvimento de processos inovadores e } \\
\text { novos métodos de trabalho. }\end{array}$ \\
\hline $\begin{array}{c}\text { Transferência de } \\
\text { Conhecimento }\end{array}$ & $\begin{array}{c}\text { Permite que os funcionários aprendam uns } \\
\text { com os outros, bem como por meio de } \\
\text { experiências e conhecimentos vindos de } \\
\text { outras organizações. }\end{array}$ & $\begin{array}{l}\text { Capacidade da organização em transferir o } \\
\text { conhecimento entre os departamentos, bem } \\
\text { como captá-lo do ambiente externo. }\end{array}$ \\
\hline $\begin{array}{c}\text { Times de Trabalho e } \\
\text { Resolução de } \\
\text { Problemas em } \\
\text { Grupo }\end{array}$ & $\begin{array}{c}\text { Nível de trabalho em grupo na organização } \\
\text { para resolução de problemas e criação de } \\
\text { ideias inovadoras. }\end{array}$ & $\begin{array}{l}\text { A estrutura e os sistemas da organização } \\
\text { encorajam o trabalho e a resolução de } \\
\text { problemas em grupo. }\end{array}$ \\
\hline
\end{tabular}

Figura 2: Dimensões da Aprendizagem Organizacional

Fonte: Elaborada a partir de Goh e Richard (1997) 
Este estudo foi validado por Angelim e Guimarães (2003) como uma importante contribuição na sistematização de formas de mensuração da $\mathrm{AO}$ no contexto de organizações públicas brasileiras.

Angelim e Guimarães (2003) conceberam duas variações para a validação da escala. Enquanto a primeira versão indicou a validade de uma solução unifatorial; a segunda, estimulada pelos autores, extraiu três fatores: 0 fator 1 diz respeito à liberdade de atuação dos funcionários; o fator 2, que se relaciona ao trabalho em grupo; e 0 fator 3 corresponde à compreensão e ao compartilhamento da missão institucional.

De acordo com Angelim e Guimarães (2003), a análise do potencial de AO pode fornecer um parâmetro sobre o nível de aprendizagem incentivado pela organização, sugerindo também a possibilidade da identificação de fatores subjacentes aos descritos por Goh e Richard (1997) por meio da replicação do OLS. Por este motivo, torna-se conveniente a aplicação da escala traduzida em novos contextos, a fim de verificar a configuração dos fatores extraídos.

Sobre a interface entre os temas abordados neste artigo, conforme Chatterjee, Pereira e Bates (2018), a cultura organizacional pode ser a facilitadora, ou a barreira, para criar e alavancar os ativos do conhecimento na organização. Assim, esses autores entendem que a aprendizagem organizacional pode ser influenciada por fatores contextuais, tais como a cultura. Por sua vez, a aprendizagem organizacional, de acordo com Douglas (1986), pode ocasionar uma reestruturação da cultura da organização, uma vez que cria no interior da organização um estado de espírito que direciona os colaboradores para o entendimento do pensamento complexo e sua aplicação ao conhecimento técnico.

\section{METODOLOGIA}

Com caráter descritivo e correlacional, na medida em que se propõe a descrever sistematicamente um fenômeno a partir de relações existentes entre variáveis (Richardson, 2017), o estudo foi conduzido por meio de uma survey, indicada para a coleta de dados primários quando se necessita de informações de um amplo número de pessoas (Hair et al., 2009).

A instituição cuja pesquisa foi aplicada possui mais de 55 anos de história e foi pioneira na interiorização do ensino superior no Brasil. Atualmente, conta com dez unidades universitárias espalhadas pelo Rio Grande do Sul, além de quatro estabelecimentos de educação básica, técnica e tecnológica. Essas unidades contribuem para o desenvolvimento local nas regiões onde são estrategicamente implantadas e recebem alunos de todos os estados do Brasil em busca de aprendizado e qualificação profissional. A instituição possui cerca de 28.700 alunos matriculados em 269 cursos e, quanto ao seu quadro de pessoal, conta com aproximadamente 2.050 docentes e 2.750 servidores técnico-administrativos. Por estar sediada em uma cidade de interior, a instituição revela-se como tradicional e uma referência em relação à sociedade, promovendo a criação e a difusão do conhecimento e os desenvolvimentos locais e regionais.

A amostra da pesquisa foi não probabilística, constituída a partir da acessibilidade do pesquisador ao campo. Sendo assim, o instrumento de coleta de dados (Anexo A) foi entregue, em formato impresso, entre os meses de março e abril do ano de 2017 a 185 (cento e oitenta e cinco) servidores lotados em um dos centros de ensino da instituição, sendo obtido um retorno de 154 (cento e cinquenta e quatro) questionários, o que corresponde a uma taxa de retorno de $83,2 \%$. Salienta-se que esse centro de ensino oferece cursos da área tecnológica e possui, ao todo, 275 (duzentos e setenta e cinco) servidores, dos quais 189 (cento e oitenta e nove) são docentes e 86 (oitenta e seis) são técnico-administrativos em educação.

Com o objetivo de mensurar os construtos Cultura Organizacional (CO) e Aprendizagem Organizacional (AO), o questionário utilizado como instrumento de coleta de dados contemplou: (i) o Instrumento Brasileiro para Avaliação da Cultura Organizacional (IBACO) validado Ferreira et al. (2002), com adaptações; (ii) a Organizational Learning Scale (OLS) de Goh e Richard (1997), com a tradução das variáveis realizada por Angelim e Guimarães (2003); e (iii) questões sociodemográficas e profissionais. Salienta-se que as adaptações realizadas consistiram na adequação de itens ao contexto da organização pesquisada (pública) e foram realizadas pelos pesquisadores para posterior validação por meio do processo de análise fatorial exploratória.

Assim, a adaptação do IBACO ocorreu em sua versão completa, sendo que foram excluídas as variáveis incompatíveis com o contexto das organizações públicas. Como resultado, o instrumento foi composto por 63 itens, em escala tipo Likert de 5 pontos, no qual o número 1 representou "não se aplica" e o número 5, "aplica-se totalmente". 
O segundo instrumento, a OLS, apresentou os 21 itens estabelecidos por Goh e Richard (1997), validados no contexto brasileiro por Angelim e Guimarães (2003). Os indivíduos responderam por meio de uma escala do tipo Likert, atribuindo valores de 1 a 5 (discordo totalmente a concordo totalmente). Por fim, o questionário foi composto por 7 questões que visavam descrever o perfil dos respondentes.

Para a análise quantitativa dos dados foi utilizado o software SPSS 20.0 (Statiscal Package for the Social Sciences), através da realização de técnicas de análise estatística simples e multivariadas, sendo utilizadas a análise fatorial exploratória e a correlação.

Primeiramente, utilizou-se a análise fatorial exploratória com a finalidade de explorar os dados das escalas adotadas neste estudo (IBACO e OLS). Com o objetivo de verificar se a análise fatorial era apropriada para 0 conjunto de dados utilizado, preliminarmente, foram realizados dois testes: o teste de esfericidade de Bartlett e 0 teste de Kaiser-Meyer-Olkin (KMO). O primeiro tem por objetivo averiguar se a correlação entre as variáveis é significativa ( $\mathrm{SIG}<0,5)$, enquanto que o segundo tem por objetivo identificar se a correlação entre os pares de variáveis pode ser explicada por outras variáveis incluídas no estudo, devendo apresentar um valor maior ou igual a 0,5 (Hair et al., 2009).

Optou-se por adotar a análise de componentes principais como método de extração dos fatores e a Varimax como método de rotação. Foram considerados os autovalores superiores a um para a definição dos fatores extraídos e a porcentagem da variância explicada pelos mesmos.

$\mathrm{Na}$ avaliação do grau de confiabilidade dos fatores, que determina o grau de consistência interna entre os indicadores de um fator, foi aplicado o Alpha de Cronbach. De acordo com Hair et al., (2009), a confiabilidade pode ser: Fraca $(a<0,6)$, Moderada $(0,6 \leq a<0,7)$, Boa $(0,7 \leq a<0,8)$, Muito Boa $(0,8 \leq a<0,9)$ ou Excelente $(a \geq$ $0,9)$.

Posteriormente, com a finalidade de identificar a existência de relações entre os fatores da $\mathrm{CO}$ e da $\mathrm{AO}$, calcularam-se os coeficientes de Correlação de Pearson. Pestana e Gageiro (2003) sugerem, por convenção, a seguinte interpretação dos coeficientes de correlação $(R)$ : Muito Baixa $(R<0,20)$, Baixa $(0,20 \leq R \leq 0,39)$, Moderada $(0,40 \leq R \leq 0,69)$, Alta $(0,70 \leq R \leq 0,89)$ ou Muito Alta $(0,90 \leq R \leq 1,00)$.

Salienta-se que o modelo teórico seguido pela pesquisa norteou a escolha das técnicas estatísticas utilizadas nas análises, conforme pode ser visualizado na Figura 3.

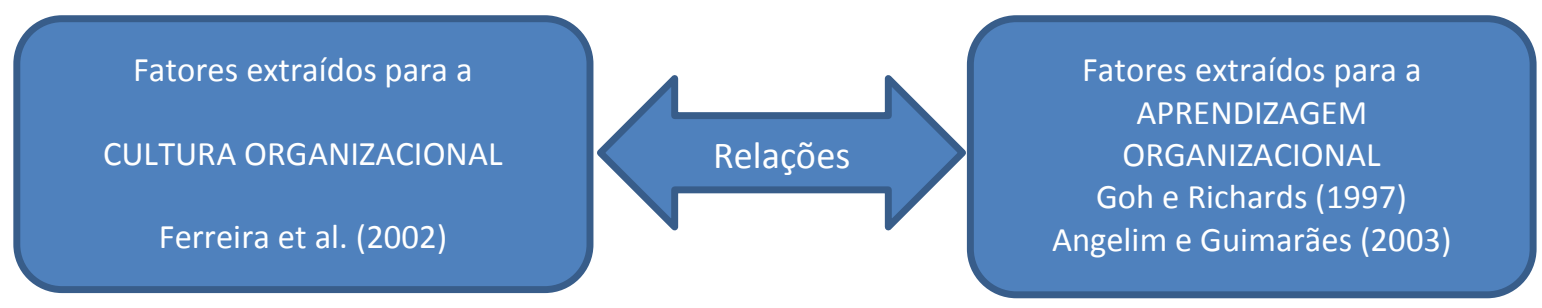

Figura 3: Modelo de Pesquisa

Fonte: Elaborada pelos autores

Conforme exposto pela Figura 1, as prévias extrações dos fatores relativos aos construtos em análise serão fundamentais para o estudo de suas relações. A próxima seção dedica-se à apresentação dos resultados encontrados em operacionalização ao método utilizado.

\section{ANÁLISE E DISCUSSÃO DOS RESULTADOS}

Os resultados que seguem apresentam a análise do perfil da amostra, as análises referentes à mensuração da $\mathrm{CO}$ e da $\mathrm{AO}$ e, por fim, as análises referentes às relações entre os construtos. 


\subsection{Perfil da Amostra}

A amostra investigada foi composta por 154 servidores de um centro da área tecnológica da universidade pesquisada. O perfil dos entrevistados, com relação a sexo, grau de escolaridade, cargo ocupado e desempenho de função encontra-se disposto na Tabela 1.

\section{Tabela 1}

Perfil dos respondentes (sexo, escolaridade, cargo e função)

\begin{tabular}{c|l|c|c}
\hline \multicolumn{1}{c|}{ Variável } & \multicolumn{1}{|c|}{ Alternativas } & Frequência & Percentual \\
\hline \multirow{4}{*}{ Sexo } & Masculino & 106 & 68,8 \\
\cline { 2 - 4 } & Feminino & 48 & 31,2 \\
& Ensino Médio & 9 & 5,8 \\
\cline { 2 - 4 } Grau de Escolaridade & Graduação & 20 & 13,0 \\
\cline { 2 - 4 } & Especialização & 23 & 14,9 \\
\cline { 2 - 4 } & Mestrado & 21 & 13,6 \\
\cline { 2 - 4 } & Doutorado & 68 & 44,2 \\
\cline { 2 - 4 } & Pós-Doutorado & 13 & 8,4 \\
\hline \multirow{3}{*}{ Cargo Ocupado } & TAE & 59 & 38,3 \\
\cline { 2 - 4 } & Docente Efetivo & 91 & 59,1 \\
\cline { 2 - 4 } & Docente Temporário & 4 & 2,6 \\
\hline \multirow{2}{*}{ Desempenha Função } & Sim & 63 & 40,9 \\
\cline { 2 - 4 } & Não & 91 & 59,1 \\
\hline
\end{tabular}

Fonte: Elaborada pelos autores.

A amostra foi composta por $68,8 \%$ de servidores do sexo masculino e $31,2 \%$ do sexo feminino. Com relação ao grau de instrução, 5,8\% possuem o ensino médio, $13,0 \%$ são graduados, $14,9 \%$ são especialistas, $13,6 \%$ são mestres, $44,2 \%$ são doutores e $8,4 \%$ são pós-doutores. No que diz respeito ao cargo ocupado, $38,3 \%$ ocupam cargos técnico-administrativos; 59,1\%, o cargo de Docente Efetivo; e 2,6\%, o cargo de Docente Temporário. Quanto ao desempenho de função gratificada, 40,9\% ocupam algum tipo de função e $59,1 \%$ não ocupam. $O$ perfil dos entrevistados relativo à idade, ao tempo de serviço e ao tempo no desempenho de função encontra-se representado na Tabela 2.

\section{Tabela 2}

Perfil dos respondentes (idade, tempo de serviço e tempo na função)

\begin{tabular}{c|c|c|c}
\hline Variável & Média & Mediana & Desvio Padrão \\
\hline Idade & 44,29 & 45,00 & 11,33 \\
\hline Tempo de Serviço & 13,70 & 10,00 & 11,79 \\
\hline Tempo no Desempenho de Função & 2,13 & 0,00 & 5,03 \\
\hline
\end{tabular}

Fonte: Elaborada pelos autores.

Observa-se que os entrevistados apresentam, em média, 44,29 anos de idade, 13,70 anos de serviço e 2,13 anos no desempenho de função gratificada.

\subsection{Mensurando a Cultura Organizacional (CO)}

Com o objetivo de realizar a análise fatorial das variáveis da escala de Cultura Organizacional (IBACO), identificou-se que os testes de adequação e de esfericidade da amostra foram considerados satisfatórios (KMO= 0,783 e sig $=0,000$ ). A seguir, foi realizada a extração dos fatores, sendo utilizados os critérios dos autovalores maiores que 1,00 e a porcentagem da variância explicada. Em decorrência, foram obtidos oito fatores com índices de Alpha de Cronbach superiores a 0,6. A Tabela 3 apresenta as variáveis que compõem os fatores da CO. 
Tabela 3

Análise Fatorial $\mathrm{CO}$

\begin{tabular}{|c|c|c|}
\hline Questão & Fatores Originais & Carga \\
\hline \multicolumn{3}{|l|}{ Fator 01: Profissionalismo Cooperativo $(\alpha=0,919)$} \\
\hline 37. O esforço e a dedicação ao trabalho são qualidades bastante apreciadas. & Profissionalismo Cooperativo & 0,767 \\
\hline 41. O profissionalismo dos servidores é visto como uma grande virtude. & Profissionalismo Cooperativo & 0,738 \\
\hline $\begin{array}{l}\text { 48. A qualidade do serviço executado é considerada uma das maiores virtudes } \\
\text { do servidor. }\end{array}$ & Profissionalismo Cooperativo & 0,736 \\
\hline $\begin{array}{l}\text { 44. A preocupação em superar as dificuldades do dia a dia é vista como de } \\
\text { grande valor. }\end{array}$ & Profissionalismo Cooperativo & 0,724 \\
\hline $\begin{array}{l}\text { 40. A capacidade de executar uma variedade de tarefas é extremamente } \\
\text { valorizada. }\end{array}$ & Profissionalismo Cooperativo & 0,668 \\
\hline $\begin{array}{l}\text { 57. Os servidores costumam ser valorizados quando alcançam metas } \\
\text { preestabelecidas. }\end{array}$ & $\begin{array}{l}\text { Práticas de Recompensa e } \\
\text { Treinamento }\end{array}$ & 0,635 \\
\hline 31. A preocupação do servidor com a qualidade de seu serviço é bem-vista. & Profissionalismo Cooperativo & 0,635 \\
\hline $\begin{array}{l}\text { 59. Os servidores que se comprometem com a missão e os ideais da Instituição } \\
\text { tornam-se modelos para os demais membros da Instituição. }\end{array}$ & Profissionalismo Cooperativo & 0,632 \\
\hline $\begin{array}{l}\text { 23. Os servidores são valorizados quando apresentam um desempenho que se } \\
\text { destaca dos demais. }\end{array}$ & $\begin{array}{c}\text { Satisfação e } \\
\text { Bem-Estar dos Servidores }\end{array}$ & 0,601 \\
\hline $\begin{array}{l}\text { 46. Os servidores que demonstram dedicação e espírito de colaboração são } \\
\text { os melhores modelos a serem seguidos. }\end{array}$ & Profissionalismo Cooperativo & 0,560 \\
\hline $\begin{array}{l}\text { 51. As ideias criativas dos servidores são postas em prática como forma de } \\
\text { torná-los mais motivados. }\end{array}$ & $\begin{array}{c}\text { Satisfação e } \\
\text { Bem-Estar dos Servidores }\end{array}$ & 0,542 \\
\hline 13. Os servidores que apresentam ideias inovadoras costumam ser valorizados. & $\begin{array}{c}\text { Satisfação e } \\
\text { Bem-Estar dos Servidores }\end{array}$ & 0,515 \\
\hline $\begin{array}{l}\text { 24. O envolvimento com os ideais da Instituição é uma atitude bastante } \\
\text { valorizada. }\end{array}$ & Profissionalismo Cooperativo & 0,512 \\
\hline 09. O espírito de colaboração é uma atitude considerada muito importante. & Profissionalismo Cooperativo & 0,445 \\
\hline $\begin{array}{l}\text { 27. Procura-se manter uma atmosfera de segurança e estabilidades para deixar } \\
\text { os servidores satisfeitos e confiantes. }\end{array}$ & $\begin{array}{c}\text { Satisfação e } \\
\text { Bem-Estar dos Servidores }\end{array}$ & 0,414 \\
\hline $\begin{array}{l}\text { 50. A criatividade é um dos requisitos básicos para a ocupação de cargos } \\
\text { gerenciais. }\end{array}$ & $\begin{array}{l}\text { Profissionalismo Competitivo } \\
\text { e Individualista }\end{array}$ & 0,409 \\
\hline $\begin{array}{l}\text { 56. Os dirigentes que inovam e promovem mudanças significativas são os } \\
\text { verdadeiros modelos a serem seguidos. }\end{array}$ & Profissionalismo Cooperativo & 0,400 \\
\hline \multicolumn{3}{|l|}{ Fator 02: Satisfação e Bem-Estar dos Servidores $(\alpha=0,834)$} \\
\hline $\begin{array}{l}\text { 26. Programas para aumentar a satisfação dos servidores são regularmente } \\
\text { desenvolvidos. }\end{array}$ & $\begin{array}{c}\text { Satisfação e } \\
\text { Bem-Estar dos Servidores }\end{array}$ & 0,763 \\
\hline $\begin{array}{l}\text { 39. Programas destinados a melhorar o bem-estar dos servidores são } \\
\text { implementados. }\end{array}$ & $\begin{array}{c}\text { Satisfação e } \\
\text { Bem-Estar dos Servidores }\end{array}$ & 0,717 \\
\hline $\begin{array}{l}\text { 22. Os servidores recebem treinamento para poderem desenvolver sua } \\
\text { criatividade. }\end{array}$ & $\begin{array}{c}\text { Satisfação e } \\
\text { Bem-Estar dos Servidores }\end{array}$ & 0,625 \\
\hline $\begin{array}{l}\text { 10. As necessidades pessoais e o bem-estar dos servidores constituem uma } \\
\text { preocupação constante da Instituição. }\end{array}$ & $\begin{array}{c}\text { Satisfação e } \\
\text { Bem-Estar dos Servidores }\end{array}$ & 0,546 \\
\hline 14. A Instituição investe no crescimento profissional dos servidores. & $\begin{array}{c}\text { Satisfação e } \\
\text { Bem-Estar dos Servidores }\end{array}$ & 0,513 \\
\hline $\begin{array}{l}\text { 36. Investe-se em um bom ambiente de trabalho com o objetivo de se garantir } \\
\text { o bem-estar dos servidores. }\end{array}$ & $\begin{array}{c}\text { Satisfação e } \\
\text { Bem-Estar dos Servidores }\end{array}$ & 0,458 \\
\hline $\begin{array}{l}\text { 05. O bem-estar dos servidores é visto como uma forma de garantir maior } \\
\text { produtividade. }\end{array}$ & $\begin{array}{c}\text { Satisfação e } \\
\text { Bem-Estar dos Servidores }\end{array}$ & 0,340 \\
\hline \multicolumn{3}{|l|}{ Fator 03: Práticas de Integração Externa com os Acadêmicos $(\alpha=0,715)$} \\
\hline $\begin{array}{l}\text { 06. } O \text { atendimento às necessidades dos alunos é uma das metas mais } \\
\text { importantes. }\end{array}$ & $\begin{array}{l}\text { Práticas de Integração } \\
\text { Externa }\end{array}$ & 0,796 \\
\hline $\begin{array}{l}\text { 15. O acompanhamento e o atendimento das necessidades dos acadêmicos } \\
\text { são feitos constantemente. }\end{array}$ & $\begin{array}{l}\text { Práticas de Integração } \\
\text { Externa }\end{array}$ & 0,722 \\
\hline 12. Persegue-se a excelência como forma de satisfazer aos acadêmicos. & $\begin{array}{l}\text { Práticas de Integração } \\
\text { Externa }\end{array}$ & 0,421 \\
\hline 01. A cooperação é mais valorizada que a competição. & Profissionalismo Cooperativo & 0,409 \\
\hline
\end{tabular}


Fator 04: Rigidez na Estrutura Hierárquica de Poder ( $\alpha=0,674)$

20. As dificuldades de ascensão profissional levam a Instituição a perder servidores.

62. É muito difícil fazer carreira dentro da Instituição.

Rigidez na Estrutura Hierárquica de Poder Rigidez na Estrutura Hierárquica de Poder

38. As oportunidades de ascensão funcional são limitadas pela rígida estrutura da Instituição.

Rigidez na Estrutura Hierárquica de Poder

(Conclusão)

Fator 05: Práticas de Relacionamento Interpessoal $(\alpha=0,613)$

02. Os servidores têm ampla liberdade de acesso aos dirigentes.

Práticas de Relacionamento $\quad 0,791$ Interpessoal

43. As relações entre servidores e membros do alto escalão são cordiais e $\quad$ Práticas de Relacionamento 0,626 amigáveis.

04. As iniciativas individuais dos servidores são estimuladas. Interpessoal

34. As mudanças são planejadas para terem efeito a curto prazo.

Profissionalismo Cooperativo $\quad 0,565$

Práticas de Integração $\quad 0,294$ Externa

Fator 06: Práticas de Recompensa e Treinamento $(\alpha=0,605)$

29. Os servidores têm uma noção clara dos principais objetivos da Instituição.

Práticas de Integração $\quad 0,688$ Externa

25. As inovações costumam ser introduzidas por meio de treinamento.

Práticas de Recompensa e $\quad 0,547$ Treinamento

53. As inovações costumam ser introduzidas por meio de programas de Práticas de Recompensa e 0,403 qualidade.

Treinamento

Fator 07: Práticas de Integração Externa com a Instituição ( $\alpha=0,721)$

17. As decisões surgem principalmente a partir da análise das necessidades da Instituição.

19. As mudanças obedecem a um planejamento estratégico.

Práticas de Integração $\quad 0,780$

Externa

Práticas de Integração $\quad 0,615$

Externa

16. A comunicação das decisões obedece à hierarquia existente na Instituição.

Práticas de Integração

0,520

Externa

03. A superação de metas preestabelecidas é uma preocupação constante.

08. As decisões mais importantes são tomadas por meio de consenso dos dirigentes.

Práticas de Integração $\quad 0,376$

Externa

Práticas de Integração $\quad 0,373$ Externa

Fator 08: Profissionalismo Competitivo e Individualista $(\alpha=0,758)$

61. A competição é valorizada, mesmo que de forma não sadia, porque o Profissionalismo Competitivo 0,840 objetivo maior da Instituição é a produtividade. e Individualista

63. A competição é vista como indispensável à obtenção de bons resultados. Profissionalismo Competitivo 0,823 e Individualista

Fonte: Elaborada pelos autores.

A amostra apresentou um comportamento diferente da escala original da Cultura Organizacional, disposta no modelo de Ferreira et al. (2002), originando um fator a mais em relação ao proposto. Sendo assim, tendo em vista a exclusão de variáveis, considerou-se o referencial teórico sobre CO para buscar identificar os principais fatores presentes nas afirmativas agrupadas em cada um dos oito fatores encontrados.

Os Fatores 03 e 07 apresentaram concentrações de questões relativas às Práticas de Integração Externa. Após a análise das questões envolvidas, optou-se por denominá-los Fator 03: Práticas de Integração Externa com os Acadêmicos e Fator 07: Práticas de Integração Externa com a Instituição. Para os demais fatores, denominaram-se, de acordo com a maior concentração de questões apresentadas, ou seja, Fator 01: Profissionalismo Cooperativo, Fator 02: Satisfação e Bem-Estar dos Servidores, Fator 04: Rigidez na Estrutura Hierárquica de Poder, Fator 05: Práticas de Relacionamento Interpessoal, Fator 06: Práticas de Recompensa e Treinamento e Fator 08: Profissionalismo Competitivo e Individualista.

Na sequência, foram identificados os índices correspondentes aos fatores da Cultura Organizacional, os quais são apresentados na Tabela 4. Considerando a escala tipo Likert de 5 pontos (1 - Não se aplica de modo algum; 5 - aplica-se totalmente), verificou-se que o Fator 05: Práticas de Relacionamento Interpessoal foi o que atingiu o maior índice médio (3,389), seguido pelo Fator 03: Práticas de Integração Externa com os Acadêmicos $(3,281)$, Práticas de Integração Externa com a Instituição $(3,201)$, Rigidez na Estrutura Hierárquica de Poder $(3,071)$, Satisfação e Bem-Estar dos Servidores $(3,048)$, Profissionalismo Cooperativo $(3,036)$, Práticas de 
Recompensa e Treinamento (2,763), sendo o Profissionalismo Competitivo e Individualista a dimensão que apresentou o menor índice $(2,726)$.

\section{Tabela 4}

Média, Mediana e Desvio Padrão dos fatores de CO

\begin{tabular}{llrc}
\multicolumn{1}{c}{ Fator } & Média & Mediana & $\begin{array}{c}\text { Desvio } \\
\text { Padrão }\end{array}$ \\
\hline Profissionalismo Cooperativo & 3,036 & 3,059 & 0,592 \\
\hline Satisfação e Bem-Estar dos Servidores & 3,048 & 3,000 & 0,612 \\
\hline Práticas de Integração Externa com os Acadêmicos & 3,281 & 3,250 & 0,701 \\
\hline Rigidez na Estrutura Hierárquica de Poder & 3,071 & 3,000 & 0,842 \\
\hline Práticas de Relacionamento Interpessoal & 3,389 & 3,333 & 0,689 \\
\hline Práticas de Recompensa e Treinamento & 2,763 & 2,667 & 0,651 \\
\hline Práticas de Integração Externa com a Instituição & 3,201 & 3,200 & 0,662 \\
\hline Profissionalismo Competitivo e Individualista & 2,726 & 3,000 & 0,925 \\
\hline
\end{tabular}

Fonte: Elaborada pelos autores com base nos dados da pesquisa.

Analisando os índices obtidos e, de acordo com a escala Likert de 5 pontos utilizada, verifica-se que seis fatores apresentaram médias superiores a 3,00, ou seja, entre "Indiferente" e "Aplica-se", com uma tendência ao "Indiferente" pelo fato de as médias situarem-se muito próximas de 3,00. Os dois fatores restantes apresentaram médias inferiores a 3,00 sendo, neste caso, entre "Não se Aplica" e "Indiferente", também com uma tendência ao "Indiferente", tendo em vista que as médias também se situam próximas de 3,00. Desta forma, de modo geral, pode-se dizer que os servidores do centro pesquisado se apresentaram indiferentes quanto à manifestação dos fatores de Cultura Organizacional.

\subsection{Mensurando a Aprendizagem Organizacional (AO)}

Visando identificar possíveis associações entre as variáveis da $A O$, de modo a agrupá-las em fatores comuns, foi realizada a análise fatorial da escala OLS, uma vez que os resultados dos testes de adequação e de esfericidade da amostra foram considerados satisfatórios $(K M O=0,849$ e sig $=0,000)$. A seguir realizou-se a extração dos fatores, sendo que foram utilizados os critérios dos autovalores maiores que 1,00 e a porcentagem da variância explicada. Com isso, foram obtidos quatro fatores com índices de Alpha de Cronbach superiores a 0,6 . A Tabela 5 apresenta as variáveis que compuseram os fatores da AO.

\section{Tabela 5}

Análise Fatorial $\mathrm{AO}$

\begin{tabular}{lcc}
\multicolumn{1}{c}{ Questão } & Fator Original & Carga \\
\hline $\begin{array}{l}\text { Fator 01: Comprometimento com a Aprendizagem Organizacional (a=0,813) } \\
\text { 69. Os novos servidores desta Instituição são encorajados a questionar o modo } \\
\text { como o trabalho é realizado. }\end{array}$ & Experimentação & 0,744 \\
\hline $\begin{array}{l}\text { 65. Existe ampla aceitação e comprometimento dos servidores para o alcance da } \\
\text { missão da Instituição. }\end{array}$ & $\begin{array}{c}\text { Clareza e Propósito da } \\
\text { Missão }\end{array}$ & 0,698 \\
\hline $\begin{array}{l}\text { 81. Os servidores desta Instituição entendem como a missão da Instituição será } \\
\text { alcançada. }\end{array}$ & $\begin{array}{c}\text { Clareza e Propósito da } \\
\text { Missão }\end{array}$ & 0,608 \\
\hline $\begin{array}{l}\text { 68. As práticas gerenciais atuais da minha Instituição encorajam os servidores a } \\
\text { resolverem problemas juntos, antes de discuti-los com um superior imediato. }\end{array}$ & $\begin{array}{c}\text { Trabalho em Equipe e } \\
\text { Grupo-Problem Solving }\end{array}$ & 0,583 \\
\hline $\begin{array}{l}\text { 74. Gestores e servidores desta Instituição compartilham de uma visão comum } \\
\text { sobre o que devem alcançar com o trabalho. }\end{array}$ & $\begin{array}{c}\text { Compromisso, Liderança } \\
\text { e Empowerment }\end{array}$ & 0,523 \\
\hline $\begin{array}{l}\text { 73. Ideias inovadoras que funcionam são frequentemente recompensadas pela } \\
\text { Instituição. }\end{array}$ & $\begin{array}{c}\text { Experimentação } \\
0,503\end{array}$ \\
\hline
\end{tabular}


(Conclusão)

Fator 02: Experimentação $(\alpha=0,623)$

71. Os gestores desta Instituição encorajam os servidores a realizar experiências $\quad$ Experimentação $\quad 0,837$ para melhorar os processos de trabalho.

75. Na Instituição em que trabalho, as novas ideias dos servidores são levadas a $\quad$ Experimentação $\quad 0,581$ sério pelos dirigentes.

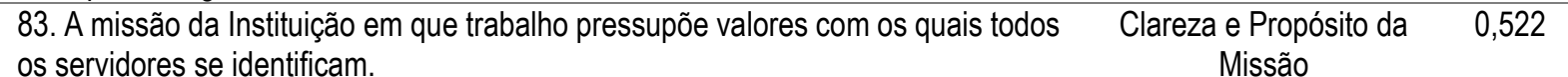
Fator 03: Compromisso, Liderança e Empowerment $(\alpha=0,728)$

78. Os gestores da Instituição em que trabalho aceitam críticas sem se tornarem Compromisso, Liderança 0,771 excessivamente defensivos.

e Empowerment

80. Nesta Instituição os gestores frequentemente oferecem um retorno que ajuda $\quad$ Compromisso, Liderança 0,558 a identificar possíveis problemas e oportunidades.

e Empowerment

79. Na Instituição em que trabalho há mecanismos que permitem aprender as Transferência de práticas de sucesso de outras Instituições.

Conhecimento

Fator 04: Transferência de Conhecimento $(\alpha=0,624)$

64. Na Instituição em que trabalho os servidores têm, frequentemente, oportunidade de conversar com outros servidores sobre experiências de trabalho bem-sucedidas.

66. Os servidores podem, frequentemente, trazer novas ideias para dentro da Instituição em que trabalho.

\begin{tabular}{lcc}
\hline 67. Fracassos são discutidos de forma construtiva em nossa Instituição. & $\begin{array}{c}\text { Transferência de } \\
\text { Conhecimento }\end{array}$ & 0,522
\end{tabular}

Fator 05: Trabalho em Equipe e Grupo-Problem Solving ( $\alpha=0,523)$

84. Na Instituição em que trabalho, a maioria dos grupos de trabalho para resolução $\quad$ Trabalho em Equipe e 0,691

de problemas é composta por servidores de distintas áreas ou setores.

Grupo-Problem Solving

77. Geralmente são criados grupos informais para resolver problemas da Trabalho em Equipe e 0,670 Instituição.

76. Os gestores desta Instituição frequentemente envolvem servidores em decisões importantes.

Grupo-Problem Solving

Compromisso, Liderança

0,584

Fonte: Elaborada pelos autores.

Tendo em vista a existência de variáveis extraídas em fatores diferentes dos originais, novamente, considerou-se o referencial teórico sobre $\mathrm{AO}$ para buscar justificar e nomear os cinco fatores encontrados. $\mathrm{O}$ Fator 01 apresentou uma maior concentração de questões relativas à Experimentação e à Clareza e ao Propósito da Missão, tendo também a presença de questões relativas a Trabalho em Equipe, e ao Comprometimento, à Liderança e ao Empowerment. Pelo conteúdo das afirmativas, optou-se por denominá-lo de Fator 01: Comprometimento com a Aprendizagem Organizacional. Para os demais Fatores, optou-se por manter a denominação que agrupou questões com maior concentração, ou seja, Fator 02: Experimentação, Fator 03: Compromisso, Liderança e Empowerment, Fator 04: Transferência de Conhecimento e Fator 05: Trabalho em Equipe e Grupo-Problem Solving (fator excluído das análises por apresentar um Alpha de Cronbach inferior a 0,6$)$.

Com o intuito de identificar os índices correspondentes à escala de $\mathrm{AO}$, calcularam-se a média, a mediana e o desvio padrão dos fatores, os quais se encontram na Tabela 6. Considerando a escala tipo Likert de 5 pontos (1 - Discordo Totalmente; 5 - Concordo Totalmente), foi possível verificar que a Experimentação foi a que atingiu o maior índice médio $(3,120)$, seguido por Compromisso, Liderança e Empowerment $(2,798)$, Clareza e Propósito da Missão (2,568), sendo o Estímulo à Transferência do Conhecimento a dimensão que apresentou o menor índice $(2,487)$.

Tabela 6

Média, Mediana e Desvio Padrão dos fatores de AO

\begin{tabular}{|c|c|c|c|}
\hline Fator & Média & Mediana & $\begin{array}{l}\text { Desvio } \\
\text { Padrão }\end{array}$ \\
\hline Comprometimento com a Aprendizagem Organizacional & 2,568 & 2,667 & 0,649 \\
\hline Experimentação & 2,798 & 3,000 & 0,638 \\
\hline Compromisso, Liderança e Empowerment & 2,487 & 2,667 & 0,712 \\
\hline Transferência de Conhecimento & 3,120 & 3,333 & 0,660 \\
\hline
\end{tabular}

Fonte: Elaborada pelos autores com base nos dados da pesquisa. 
Pela análise dos índices obtidos e levando em conta a escala Likert de 5 pontos utilizada, foi possível verificar que quatro fatores apresentaram médias inferiores a 3,00, ou seja, entre "Discordo" e "Indiferente", com uma tendência ao "Indiferente" pelo fato das médias situarem-se muito próximas de 3,00. 0 fator restante apresentou média superior a 3,00 e, neste caso, entre "Indiferente" e "Concordo", também com uma tendência ao "Indiferente" pela proximidade de 3,00. Desta forma, em média, pode-se dizer que os servidores do centro de ensino pesquisado apresentam-se indiferentes quanto aos fatores identificados para a AO.

\subsection{Relações entre $\mathrm{CO}$ e $\mathrm{AO}$ na instituição pesquisada}

Com a finalidade de identificar a existência de relações entre os fatores da $\mathrm{CO}$ e da $\mathrm{AO}$ no contexto pesquisado, calcularam-se os coeficientes de Correlação de Pearson, conforme apresentado na Tabela 7.

\section{Tabela 7}

Matriz de Correlações entre Fatores de $\mathrm{CO}$ e AO

\begin{tabular}{|c|c|c|c|c|c|c|c|c|}
\hline Fatores & FATC01 & FATC02 & FATC03 & FATC04 & FATC05 & FATC06 & FATC07 & FATC08 \\
\hline$\overline{\text { FATA01 }}$ &, $592^{*}$ &, $429^{*}$ &, $507^{*}$ &,- 048 &, $338^{*}$ &, $513^{*}$ &, $569^{\circ}$ &, 106 \\
\hline $\begin{array}{l}\text { FATA02 } \\
\end{array}$ & ,623* & $4449^{*}$ & ,442* &,$- 262^{*}$ & $378^{*}$ &, $328^{*}$ & $333^{\prime \prime}$ &,- 026 \\
\hline FATA03 &, $486^{*}$ &, $353^{*}$ &, $471^{* *}$ &,$- 212^{*}$ & $332^{*}$ &, $374^{*}$ & $427^{\circ}$ &, 004 \\
\hline$\overline{\text { FATA04 }}$ & $480^{*}$ & $446^{*}$ & $423^{* *}$ & $\mid-134$ & $446^{* *}$ & $290^{\circ}$ & $.331^{\prime \prime}$ & .013 \\
\hline
\end{tabular}

**. Correlation is significant at the 0.01 level (2-tailed).

\begin{tabular}{l|l}
\hline FATC: Fator relativo à Cultura Organizacional & FATA: Fator relativo à Aprendizagem Organizacional
\end{tabular}

Fonte: Elaborada pelos autores.

Para a análise das associações entre fatores, apresentada a seguir, foi utilizada a interpretação indicada por Pestana e Gageiro (2003), disposta no método do estudo. Por meio da Tabela 9, é possível perceber que a maior associação significativa e positiva encontrada, entre os fatores da $\mathrm{CO}$ e os fatores da AO, é 0,623 e referese aos fatores Profissionalismo Cooperativo (FATC01) e Experimentação (FATA02), sendo esta considerada uma associação moderada. Por ser uma associação positiva, pode-se inferir que, quanto mais elevada for a percepção de um dos fatores (Profissionalismo Cooperativo/Experimentação), mais elevada será a percepção do outro. Esse resultado indica que a percepção de uma cultura propícia à valorização dos colaboradores, na qual está presente o espírito de colaboração, dedicação, profissionalismo e capacidade de iniciativa (Ferreira et al. (2002), relaciona-se ao encorajamento para o desenvolvimento de novos processos ou métodos de trabalho, atuando para a liberdade quanto à experimentação por parte dos funcionários (Goh \& Richard,1997).

Além disso, destaca-se que os fatores de CO Profissionalismo Cooperativo (FATC01) e Práticas de Integração Externa com os Acadêmicos (FATC03) possuem associações significativas positivas moderadas $(0,40 \leq R \leq 0,69)$ com todos os fatores de AO. Esse resultado revela que o espírito de colaboração, juntamente com o foco no atendimento das necessidades do público externo (acadêmicos da instituição), são fatores da cultura que possuem relação com a aprendizagem organizacional em todas as suas dimensões de análise.

Vale ressaltar que fatores de CO Satisfação e Bem-Estar dos Servidores (FATC02), Práticas de Relacionamento Interpessoal (FATC05), Práticas de Recompensa e Treinamento (FATC06) e Práticas de Integração Externa com a Instituição (FATC07) também apresentaram correlações positivas significativas com todos fatores de $A O$, porém estas variaram entre baixas $(0,20 \leq R \leq 0,39)$ e moderadas $(0,40 \leq R \leq 0,69)$.

$\mathrm{Na}$ análise das associações negativas, o maior valor significativo encontrado foi de $-0,262$, correspondente à relação entre o fator Rigidez na Estrutura Hierárquica de Poder (FATC04) e Experimentação (AO), sendo esta considerada uma associação baixa. Por se tratar de uma associação negativa, infere-se que o aumento da percepção de um dos fatores (Rigidez na Estrutura Hierárquica de Poder/Experimentação) ocasiona uma diminuição na percepção do outro. O fator de CO Rigidez na Estrutura Hierárquica de Poder também apresenta uma correlação significativa e negativa com o fator de AO Compromisso, Liderança e Empowerment (FATA03), com baixa associação $(R=-0,212)$. Esses resultados indicam que, quanto maiores as dificuldades percebidas de ascensão profissional e de carreira decorrentes de uma estrutura hierárquica rígida (Ferreira et al. (2002), menores serão as avaliações sobre a aprendizagem decorrente do estímulo a experiências e a novas ideias, bem como da aprendizagem decorrente da empatia e do apoio dos gestores da instituição (Goh \& Richard,1997). 
Os resultados da pesquisa permitem conceber os construtos, $\mathrm{CO}$ e AO, como relacionados no contexto pesquisado. Com exceção de dois fatores de CO (Rigidez na Estrutura Hierárquica de Poder - FATC04 e Profissionalismo Competitivo e Individualista - FATC08), os demais apresentam relações significativas e positivas com todos os fatores de AO. Por outro lado, o fator de CO Rigidez na Estrutura Hierárquica de Poder (FATC04) possui associação significativa e negativa com dois fatores de $A O$ (Experimentação e Práticas de Integração Externa com os Acadêmicos). Por fim, destaca-se a não existência de associação significativa do fator de CO Profissionalismo Competitivo e Individualista (FATC08) com nenhum dos fatores de AO.

Considerando a aprendizagem 0 ato de evidenciar a experiência contínua (Weick \& Westley, 2004), os achados da presente pesquisa revelam como relacionados aqueles aspectos da cultura organizacional conexos à cooperação, à integração e à experimentação em detrimento de manifestações de estruturas rígidas de poder e competição na organização. Dada a natureza da organização pesquisada - pública -, os resultados encontrados transpassam alguns de seus valores proeminentes, tais como a cooperação, a democracia, a participação e a integração.

\section{CONSIDERAÇÕES FINAIS}

Por meio da avaliação da percepção dos servidores lotados no centro de ensino pesquisado, foi possível identificar e compreender as relações existentes entre os fatores da Cultura Organizacional e da Aprendizagem Organizacional.

Em relação à $\mathrm{CO}$, quanto aos fatores comumente adotados pelos servidores, foi possível a identificação de oito fatores com confiabilidade satisfatória (Profissionalismo Cooperativo; Satisfação e Bem-Estar dos Servidores; Práticas de Integração Externa com os Acadêmicos; Rigidez na Estrutura Hierárquica de Poder; Práticas de Relacionamento Interpessoal; Práticas de Recompensa e Treinamento; Práticas de Integração Externa com a Instituição; Profissionalismo Competitivo e Individualista).

No que diz respeito aos fatores potencializadores da AO no contexto pesquisado, após a análise fatorial, foram extraídos quatro fatores com confiabilidade satisfatória (Comprometimento com a Aprendizagem Organizacional; Experimentação; Compromisso, Liderança e Empowerment; Transferência de Conhecimento).

Salienta-se que, entre os resultados descritivos para os ambos os construtos ( $\mathrm{CO}$ e AO), os índices referentes às médias dos fatores expuseram uma postura de indiferença por parte dos servidores diante da maioria das afirmativas presentes no questionário (médias entre 2,48 e 3,38). Estes resultados sugerem que a instituição pode estar negligenciando alguns aspectos referentes ao estabelecimento de padrões, valores e normas que conduzam suas atividades, bem como desprezando a construção e o desenvolvimento de competências necessárias à aprendizagem na organização.

$\mathrm{O}$ estudo das correlações entre $\mathrm{CO}$ e $\mathrm{AO}$ permitiu identificar que os construtos possuem associações entre a maior parte de seus fatores, sendo que as relações significativas positivas tomaram destaque. Com exceção de dois fatores de CO (Rigidez na Estrutura Hierárquica de Poder e Profissionalismo Competitivo e Individualista), os outros seis apresentaram relações significativas e positivas com todos os fatores de AO. Enquanto o fator de $\mathrm{CO}$ Rigidez na Estrutura Hierárquica de Poder apresentou associação significativa e negativa com dois fatores de AO, o fator de CO Profissionalismo Competitivo e Individualista não apresentou associação significativa com nenhum dos fatores de $\mathrm{AO}$.

Em termos gerais, os resultados da pesquisa permitiram identificar um entrelaçamento entre os temas no contexto pesquisado em sintonia com o disposto na literatura (Douglas, 1986; Dogson, 1993; Tonet, 2008, Weick \& Westley, 2004).

Entre as limitações do estudo, pode-se citar o tipo de amostra, não probabilística, não permitindo inferências além do contexto. Mesmo se tratando de um estudo quantitativo, a generalização dos resultados não pode ser estendida aos demais centros de ensino e nem mesmo à própria instituição. Sugere-se, para estudos futuros, a replicação em outros contextos, a fim de verificar se relações encontradas aqui encontradas serão corroboradas.

\section{REFERÊNCIAS}

Angelim, G. P., \& Guimarães, T. A. (2003). Potencial de aprendizagem organizacional e qualidade de gestão: um estudo multicaso em organizações públicas brasileiras. Anais do 27 Encontro da ANPAD, 1-16. 
Antonello, C. S. (2006). Aprendizagem na ação revisitada e sua relação com a noção de competência. Comportamento organizacional e gestão, 12(2), 199-220.

Argyris, C., \& Schon, D. A. (1978). Organization learning: a theory of action perspective. Massachusetts: Addison Wesley.

Argyris, C., \& Schön, D. A. (1996). Organizational Learning II: theory, method and practice. Massachusetts: Addison Wesley.

Chatterjee, A., Pereira, A., \& Bates, R. (2018). Impact of individual perception of organizational culture on the learning transfer environment. International Journal of Training and Development, 22(1), 15-33.

Daft, R. L., \& Weick, K. E. (1984). Toward a model of organizations as interpretation systems. Academy of management review, 9(2), 284-295.

Dodgson, M. (1993). Organizational learning: a review of some literatures. Organization studies, 14(3), 375-394.

Ferreira, M. C., Assmar, E. M. L., Estol, K. M. F., Helena, M. C. C. C., \& Cisne, M. D. C. F. (2002). Desenvolvimento de um instrumento brasileiro para avaliação da cultura organizacional. Estudos de Psicologia, 7(2), 271-280.

Ferreira, M.C.; \& Assmar, E.M.L. (2008). Cultura Organizacional. In: Siqueira, M.M.M. (Org.) Medidas do Comportamento Organizacional: Ferramentas de diagnóstico e de gestão. Porto Alegre: Artmed.

Fiol, C. M., \& Lyles, M. A. (1985). Organizational learning. Academy of management review, 10(4), 803-813.

Fleury, M. T. (1996). O desvendar a cultura de uma organização - uma discussão metodológica. In: Fleury, M.T.L., \& Fischer, R.M. (coord.). Cultura e poder nas organizações. São Paulo: Atlas.

Goh, S., \& Richards, G. (1997). Benchmarking the learning capability of organizations. European Management Journal, 15(5), 575-583.

Hair, J. F., Black, W. C., Babin, B. J., Anderson, R. E., \& Tatham, R. L. (2009). Análise multivariada de dados (6 ${ }^{a}$ ed.). Porto Alegre: Bookman Editora.

Helmsing, B. (2001). Externalities, learning and governance: new perspectives on local economic development. Development and change, 32(2), 277-308.

Kim, D. H. (1993). The link between individual and organizational learning. Sloan Management Review, 35, 37-50.

Kim, D. H. (1998). $O$ elo entre a aprendizagem individual e a aprendizagem organizacional. In: Klein. A gestão estratégica do capital intelectual: recursos para a economia baseada em conhecimento. Rio de Janeiro: Qualitymark, 61-92.

Lee, S., Rittiner, F., \& Szulanski, G. (2016). The Past, present, and future of organizational learning research: A conversation with professor Linda Argote. Journal of Management Inquiry, 25(1), 85-92.

Levitt, B., \& March, J. G. (1988). Organizational learning. Annual review of sociology, 14(1), 319-338.

Nogueira, R. A., \& Odelius, C. C. (2015). Desafios da pesquisa em aprendizagem organizacional. Cadernos Ebape. $B R, 13(1), 83-102$.

Normann, R. (1985). Developing capabilities for organizational learning. In J. M. Pennings \& Associates (Eds.) Organizational strategy and change: New views on formulating and implementing strategic decisions. San Francisco: Jossey-Bass, 217-248.

Pestana, M. H., \& Gageiro, J. N. (2003). Análise de dados para ciências sociais: a complementaridade do SPSS ( $3^{\mathrm{a}}$ ed.). Lisboa: Silabo.

Probst, G. J. B., \& Büchel, B. S. T. (1997). Learning Organization: the competitive advantage of the future. London: Pretence Hall.

Richardson, R. J. (2017). Pesquisa social: métodos e técnicas (4. ed.). São Paulo: Atlas.

Schein, E. H. (1984). Coming to a new awareness of organizational culture. Sloan management review, 25(2), 316.

Schein, E. (2009). Cultura Organizacional e Liderança. São Paulo: Atlas.

Sweringa. J., \& Wierdsma, A. (1995). La organización que aprende. Wilmington: Addison-Wesley.

Revista Alcance - Eletrônica - vol. 25 - n. 3 - Set./Dez. 2018 
Tang, M., \& Zhang, T. (2016). The impacts of organizational culture on information security culture: a case study. Information Technology and Management, 17(2), 179-186.

Tonet, H. (2008). O desafio de compartilhar e disseminar conhecimento nas organizações. In: Angeloni, M. T. Gestão do conhecimento no Brasil: casos experiências e práticas de empresas públicas. Rio de Janeiro: Qualitymark.

Takahashi, A. R. W., \& Fischer, A. L. (2009). Debates passados, presentes e futuros da aprendizagem organizacional: um estudo comparativo entre a produção acadêmica nacional e internacional. RAM. Revista de Administração Mackenzie (Online), 10(5), 53-76.

Wang, C. L., \& Ahmed, P. K. (2003). Organisational learning: a critical review. The learning organization, 10(1), 817.

Weick, K. E., \& Westley, F. (2004). Aprendizagem organizacional: confirmando um oximoro. In: Clegg, S., Hardy, C., \& Nord, W. R. (org.) Handbook de estudos organizacionais (v.3). São Paulo: Atlas, 361-388. 


\section{Anexo A - Instrumento de coleta de dados}

\section{Cultura Organizacional}

1. A cooperação é mais valorizada que a competição.

2. Os servidores têm ampla liberdade de acesso aos dirigentes.

3. A superação de metas preestabelecidas é uma preocupação constante.

4. As iniciativas individuais dos servidores são estimuladas.

5. O bem-estar dos servidores é visto como uma forma de garantir maior produtividade.

6. 0 atendimento às necessidades dos alunos é uma das metas mais importantes.

7. Não há figuras importantes que possam servir de exemplo para os servidores.

8. As decisões mais importantes são tomadas através de consenso dos dirigentes.

9. O espírito de colaboração é uma atitude considerada muito importante.

10. As necessidades pessoais e o bem-estar dos servidores constituem uma preocupação constante da instituição.

11. Os servidores com desempenho permanentemente baixo são demitidos.

12. Persegue-se a excelência como forma de satisfazer aos acadêmicos.

13. Os servidores que apresentam ideias inovadoras consumam ser valorizados.

14. A instituição investe no crescimento profissional dos servidores.

15. 0 acompanhamento e 0 atendimento das necessidades dos acadêmicos são feitos constantemente.

16. A comunicação das decisões obedece à hierarquia existente na instituição.

17. As decisões surgem principalmente a partir da análise das necessidades da instituição.

18. Mantêm-se relações amigáveis com os acadêmicos.

19. As mudanças obedecem a um planejamento estratégico.

20. A dificuldade de ascensão profissional leva a instituição a perder servidores.

21. Os chefes imediatos são como pais para os servidores.

22. Os servidores recebem treinamento para poderem desenvolver sua criatividade.

23. Os servidores são valorizados quando apresentam um desempenho que se destaca dos demais.

24. O envolvimento com os ideais da instituição é uma atitude bastante valorizada.

25. As inovações costumam ser introduzidas através de treinamento.

26. Programas para aumentar a satisfação dos servidores são regulamente desenvolvidos.

27. Procura-se manter uma atmosfera de segurança e estabilidade para deixar os servidores satisfeitos e confiantes.

28. É prática comum a comemoração dos aniversários pelos servidores.

29. Os servidores têm uma noção clara dos principais objetivos da instituição.

30. A criatividade não é valorizada como deveria ser.

31 A preocupação do servidor com a qualidade de seu serviço é bem-vista.

32. Não há espaço para iniciativas individuais dos servidores.

33. Ser cordial com os colegas é uma das atitudes mais estimuladas.

34. As mudanças são planejadas para terem efeito a curto prazo.

35. Os familiares dos servidores costumam também participar dos eventos e festas.

36. Investe-se em um bom ambiente de trabalho com o objetivo de se garantir o bem-estar dos servidores.

37. O esforço e a dedicação ao trabalho são qualidades bastante apreciadas.

38. As oportunidades de ascensão funcional são limitadas pela rígida estrutura da instituição.

39. Programas destinados a melhorar o bem-estar dos servidores são implementados.

40. A capacidade de executar uma variedade de tarefas é extremamente valorizada.

41. O profissionalismo dos servidores é visto como uma grande virtude.

42. A ascensão profissional é uma decorrência natural do mérito e competência dos empregados.

43. As relações entre servidores e membros do alto escalão são cordiais e amigáveis.

44. A preocupação em superar as dificuldades do dia a dia é vista como de grande valor.

45. As promoções são definidas por avaliação de desempenho.

46. Os servidores que demonstram dedicação e espírito de colaboração são os melhores modelos a serem seguidos.

47. As pessoas que fazem carreira rapidamente são as que demonstram maiores conhecimentos dentro de suas áreas.

48. A qualidade do serviço executado é considerada uma das maiores virtudes do servidor.

49. Somente os bons servidores recebem benefícios que lhes garantem um melhor bem-estar. 
50. A criatividade é um dos requisitos básicos para a ocupação de cargos gerenciais.

51. As ideias criativas dos servidores são postas em prática como forma de torná-los mais motivados.

52. O crescimento profissional é considerado indispensável à permanência dos servidores na instituição.

53. As inovações costumam ser introduzidas através de programas de qualidade.

54. Os servidores se relacionam como se fossem uma grande família.

55. As iniciativas dos servidores são incentivadas, mas ficam sob a controle de seus chefes imediatos.

56. Os dirigentes que inovam e promovem mudanças significativas são os verdadeiros modelos a serem seguidos.

57. Os servidores costumam ser valorizados quando alcançam metas preestabelecidas.

58. Metas pessoais, quando de grande valor, são incorporadas às metas organizacionais.

59. Os servidores que se comprometem com a missão e os ideais da instituição tomam-se modelos para os demais membros.

60. Existem normas que estabelecem o grau de participação dos servidores no processo de tomada de decisões. 61. A competição é valorizada, mesmo que de forma não sadia, porque o objetivo maior da instituição é a produtividade.

62. É muito difícil fazer carreira dentro da instituição.

63. A competição é vista como indispensável à obtenção de bons resultados.

\section{Aprendizagem Organizacional}

64. Na instituição em que trabalho os servidores têm, frequentemente, oportunidade de conversar com outros servidores sobre experiências de trabalho bem-sucedidas.

65. Existe ampla aceitação e comprometimento dos servidores para o alcance da missão da instituição.

66. Os servidores podem, frequentemente, trazer novas ideias para dentro da instituição em que trabalho.

67. Fracassos são discutidos de forma construtiva em nossa instituição.

68. As práticas gerenciais atuais da minha instituição encorajam os servidores a resolverem problemas juntos, antes de discuti-los com um superior imediato.

69. Os novos servidores desta instituição são encorajados a questionar o modo como o trabalho é realizado.

70. Nesta instituição os gestares resistem a mudanças e a novas ideias.

71. Os gestores desta instituição encorajam os servidores a realizar experiências para melhorar os processos de trabalho.

72. Novos processos de trabalho, que podem ser úteis para a instituição, são geralmente compartilhados com todos os servidores.

73. Ideias inovadoras que funcionam são frequentemente recompensadas pela instituição.

74. Gestores e servidores desta instituição compartilham de uma visão comum sobre o que devem alcançar com o trabalho.

75. Na instituição em que trabalho, as novas ideias dos servidores são levadas a sério pelos dirigentes.

76. Os gestores desta instituição frequentemente envolvem servidores em decisões importantes.

77. Geralmente são criados grupos informais para resolver problemas da instituição.

78. Os gestores da instituição em que trabalho aceitam críticas sem se tornarem excessivamente defensivos.

79. Na instituição em que trabalho há mecanismos que permitem aprender as práticas de sucesso de outras organizações.

80. Nesta instituição os gestores frequentemente oferecem um retorno que ajuda a identificar possíveis problemas e oportunidades.

81. Os servidores desta instituição entendem como a missão organizacional será alcançada.

82. Os servidores têm oportunidades de realizar autoavaliação com relação ao alcance dos objetivos organizacionais.

83. A missão da instituição em que trabalho pressupõe valores com os quais todos os servidores se identificam.

84. Na instituição em que trabalho, a maioria dos grupos de trabalho para resolução de problemas é composta por servidores de distintas áreas ou setores.

\section{Perfil}

1. Idade: _ anos.

2. Sexo: ( ) Feminino ( ) Masculino

3. Grau de escolaridade: ( ) Ensino Médio ( ) Graduação ( ) Especialização ( ) Mestrado ( ) Doutorado

( ) Pós-doutorado

4. Qual cargo você ocupa atualmente?

( ) Técnico-Administrativo em Educação Classe A ( ) Técnico-Administrativo em Educação Classe B 
( ) Técnico-Administrativo em Educação Classe C ( ) Técnico-Administrativo em Educação Classe D

( ) Técnico-Administrativo em Educação Classe E ( ) Docente efetivo ( ) Professor Substituto /temporário

5. Qual a função que você ocupa atualmente na instituição? ( ) não ocupo função ( ) Ocupo função. Qual?

6. Há quanto tempo você trabalha na UFSM?

7. Há quanto tempo você exerce a função atual? anos. anos. 